\title{
NEUTRON CAPTUE PROMPT GAMMA-RAY ACTIVATION ANALYSIS AT THE NIST COLD NEUTRON RESEARCH FACILITY
}

\author{
R. M. LINDSTROM, ${ }^{*}$ R. ZEISLER, ${ }^{*}$ D. H. VINCENT, ${ }^{* 2}$ R. R. GREENBERG, ${ }^{*}$ C. A. STONE, ${ }^{* 3}$ E. A. \\ MACKEY," D. L. ANDERSON, ${ }^{* *}$ D. D. CLARK $* *$ \\ *National Institute of Standards and Technology, Gaithersburg, MD 20899 (USA) \\ "*Food and Drug Administration, Washington, DC 20204 (USA) \\ ${ }^{* * *}$ Cornell University, Ithaca, NY 14853 (USA)
}

(Received September 22, 1992)

\begin{abstract}
An instrument for neutron capture prompt gamma-ray activation analysis (PGAA) has been constructed as part of the Cold Neutron Research Facility at the $20 \mathrm{MW}$ National Institute of Standards and Technology Research Reactor. The neutron fluence rate (thermal equivalent) is $1.5 \cdot 10^{8} \mathrm{n} \cdot \mathrm{cm}^{-2}$. $\mathbf{s}^{-1}$, with negligible fast neutrons and gamma-rays. With compact geometry and hydrogen-free construction, the sensitivity is sevenfold better than an existing thermal instrument. Hydrogen background is thirty fold lower.
\end{abstract}

\section{Introduction}

The analytical advantages of cold neutrons for prompt gamma-ray activation analysis (PGAA) have been described elsewhere in these proceedings. ${ }^{1}$ The present work describes the implementation of a permanent, full-time analytical instrument at the Cold Neutron Research Facility at the National Institute of Standards and Technology (NIST) Research Reactor. In its design we have benefited from the experience gained since 1977 with the University of Maryland (UMd)-NIST thermal PGAA instrument at this reactor 2,3, and in collaboration since 1986 with the cold-neutron facility at the German Research Center in Jülich. 1,4

The UMd-NIST system has proven to be useful for determining boron in a wide variety of matrices from atmospheric filters to steels, for measuring a number of major and minor elements in foods ${ }^{5}$ and other biological materials, and for the multielement determination of the constituents of atmospheric aerosols. ${ }^{6}$ Limitations have been set by the relatively low elemental sensitivities (so that irradiation times of many hours are typical), and by the need to dismantle and rebuild the system between fuel cycles to allow access to the reactor top. Because the nominally thermal beam contains about $2 \%$ epicadmium neutrons, the neutron shielding around the apparatus necessarily contains large amounts of thermalizing material in the form of paraffin; consequently, the counting rate of hydrogen in the background is equivalent to about $1 \mathrm{mg}$ in the sample. Thus, this system is not usable for the determination of trace amounts of hydrogen, an element of great interest in materials science.

Present addresses: ${ }^{1}$ International Atomic Energy Agency, Vienna (Austria), ${ }^{2}$ University of Michigan, Ann Arbor, MI 48109 (USA), ${ }^{3}$ San Jose State University, San Jose, CA 95192 (USA). 


\section{The NIST Cold Neutron Research Facility (CNRF) and the PGAA instrument}

The neutron guides and the instruments which comprise the CNRF are in the final stages of construction. The project has been described in detail. ${ }^{7}$ Eight beam ports supply neutrons to fourteen instruments for materials science, fundamental physics, and analytical chemistry measurements (Fig. 1). The CNRF and most of its instruments are operated as a national facility, and as such are open to qualified investigators on the basis of reviewed experimental proposals. Two of these instruments are used for analytical chemistry: one for neutron depth profiling ${ }^{8}$ and one for PGAA.

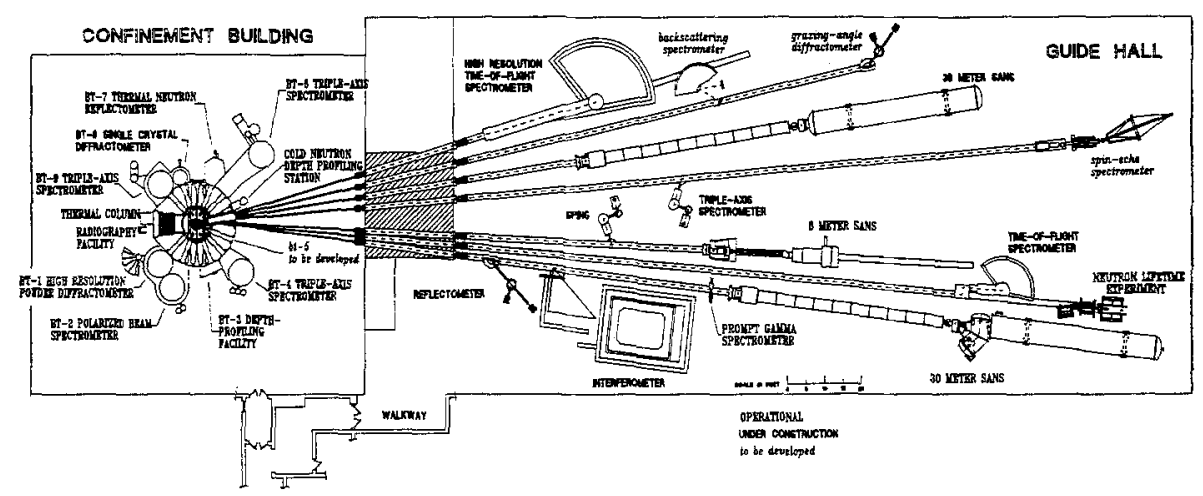

Fig 1. Plan of the NIST reactor and the Cold Neutron Research Facility, showing the instruments installed and planned. The guide hall dimensions are $30.5 \times 61 \mathrm{~m}$.

The heavy-water NIST research reactor operates continuously for four-week fuel cycles at $20 \mathrm{MW}$. Long-wavelength "cold" neutrons are produced in a 16- $\mathrm{L}_{2} \mathrm{O}$ ice moderator at about $30 \mathrm{~K}$ near the reactor core, pass through a neutron guide, and are filtered through $127 \mathrm{~mm}$ of Be and $178 \mathrm{~mm}$ of single-crystal Bi (both at $77 \mathrm{~K}$ ) before reaching the PGAA station in the guide hall. The resulting neutron beam has a wavelength greater than the $\mathrm{Be}$ Bragg cutoff of $0.4 \mathrm{~nm}$ (velocity less than $1000 \mathrm{~m} / \mathrm{s}$ ), with negligible contamination by epithermal and fast neutrons and reactor gamma rays. The fluence rate at the PGAA target position $41 \mathrm{~m}$ from the cold source was measured to be $1.5 \times 10^{8} \mathrm{n} \cdot \mathrm{cm}^{-2} \cdot \mathrm{s}^{-1}$ (thermal equivalent: using $\sigma=\sigma_{\mathrm{th}}=98.65 \mathrm{~b}$ for a $25-\mu \mathrm{m}$ Au foil) at $20 \mathrm{MW}$. Because of the purity of the neutron beam, neutron and gamma-ray shielding requirements are modest and scatter-capture background is low. In the present system, particular care has been taken in the design of the target holder and detector assembly to avoid hydrogen in materials of construction. The apparatus is shown in Fig. 2.

The PGAA beam comprises the lower $45 \times 50 \mathrm{~mm}$ half of neutron guide NG7. The upper $50 \times 50 \mathrm{~mm}$ beam continues past the PGAA station for another $2 \mathrm{~m}$ to the velocity selector of a 30-m SANS instrument. The $1-\mathrm{m}$ guide section adjacent to the PGAA station is made of boron-free glass instead of the borosilicate that is used for other guides, in order to avoid a high background from boron capture gamma rays. Neutrons which escape from this guide section are absorbed by coating the outside of the guide with a graphite-based paint heavily loaded with ${ }^{6} \mathrm{LiF}$ and low in hydrogen. ${ }^{9}$ 
The neutron beam emerges from the evacuated guide into air through a window of magnesium alloy $0.25 \mathrm{~mm}$ thick. A shutter outside the window, made of ${ }^{6} \mathrm{Li}$ glass, ${ }^{10}$ opens to admit the neutrons to the target. This silicate glass contains $8 \%(\mathrm{w} / \mathrm{w})^{6} \mathrm{Li}$, which gives a gamma-free attenuation coefficient of $0.7 \mathrm{~mm}^{-1}$ for thermal neutrons. The glass slab which forms the bottom of the guide above the PGAA station is capped with 6Li glass to avoid

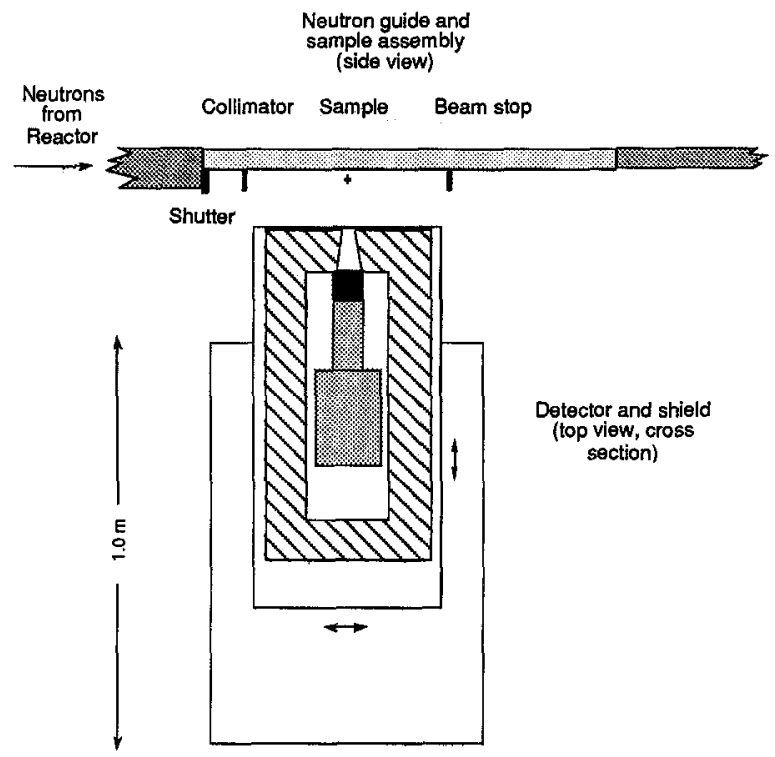

Fig. 2. Scale drawing of the PGAA spectrometer. The detector and shield are shown in cross section from the top and the guide is shown from the side, rotated about the sample position.

background from neutron scattering and capture. A pierced plate of fused ${ }^{6} \mathrm{Li}_{2} \mathrm{CO}_{3}{ }^{11}$ placed just behind the shutter, collimates the neutron beam to a circle $20 \mathrm{~mm}$ in diameter. Access to the PGAA target position, and thus the maximum sample size, is constrained by the need to operate as close as $30 \mathrm{~mm}$ from the guide above. Sample targets are usually held in the beam in envelopes of 25- $\mu \mathrm{m}$ Teflon FEP film, suspended by monofilament Teflon strings between the prongs of a supporting fork. A beam stop of ${ }^{6} \mathrm{Li}$ glass absorbs the residual beam passing through the target. The collimator and beam stop are positioned on an optical bench attached to the rigid aluminum table that carries the sample support. When it is necessary to reduce air scattering, the volume between the neutron collimator and the beam stop can be flooded with $\mathrm{He}$ at atmospheric pressure in a Teflon tent.

A Ge gamma-ray detector ( $27 \%$ relative efficiency, $1.7 \mathrm{keV}$ resolution, with a resistive feedback preamplifier and 3-L Dewar), with its axis at right angles to the neutron beam, views the target through a ${ }^{6} \mathrm{Li}$-glass window. The detector system was chosen and tuned for the maximum throughput of high-energy events with acceptable resolution. Gamma-ray spectra are acquired with a 16384-channel fixed conversion time analog-digital converter (Canberra Nuclear Data ND582) coupled to a multichannel pulse height analyzer (ND556 AIM). The AIM is controlled via the building-wide Ethernet via Nuclear Data acquisition and display software on a VAXstation 3100 . 
Environmental gamma radiation is reduced by shielding the detector with at least $100 \mathrm{~mm}$ of lead in all directions. The lead in turn is shielded from stray neutrons (which produce $7-\mathrm{MeV} \mathrm{Pb}$ capture gamma rays) with sheets of boral. The field of view of the detector is collimated so as to receive gamma rays chiefly from the target. The shielded detector is supported on a table, the top of which is moved vertically and parallel to the beam on threaded rods. The table rolls on a track perpendicular to the beam to adjust the counting distance, which can be as close as $190 \mathrm{~mm}$ from the center of the target to the front face of the detector.

\section{Results and discussion}

The cold-neutron PGAA instrument has been in a research mode since the first neutrons became available in the guide hall in late 1990. Experiments to characterize the system and subsequent changes to improve its operation, such as optimized shielding in the vicinity of the target-detector assembly, have been continual.

Largely as a result of the compact target-to-detector geometry, the sensitivity (counting rate per gram of analyte) is better by a factor of 7.5 than that obtained with the existing UMd-NIST instrument. The hydrogen background counting rate at present corresponds to $40 \mu \mathrm{g} \mathrm{H}$, which is lower by a factor of thirty than that of the older system. It is expected that, when all the neutron and gamma-ray shielding is in place, measurements of hydrogen well below $10 \mu \mathrm{g}$ will be within reach, even without the use of a helium atmosphere in the target chamber.

Neutron capture by silicon in the glass of the adjacent guide produces strong $\mathrm{Si}$ peaks in the background spectrum. Although these peaks are useful for energy calibration and fluence monitoring, their presence makes the background at all energies higher than if the PGAA station were installed at the end of the guide. Because of capture in the shutter glass, the Si background is measurably higher when the shutter is closed than when it is open. The intensity of the continuum below $500 \mathrm{keV}$ is substantially less than that observed with the thermal system, and comparable to early measurements in Jülich. ${ }^{4}$ All significant gamma-ray peaks in the background spectrum between 1000 and $5500 \mathrm{keV}$ (except $\mathrm{H}$ at 2223 $\mathrm{keV})$ are from silicon; at higher energy, capture peaks from the nickel lining of the guide are detectable. With the shutter open, nitrogen and even argon capture gamma rays appear in the spectrum because of capture in the air-filled beam path. Secondary fast neutrons, generated in the collimator and beam stop by interactions of the fast tritons from the ${ }^{6} \mathrm{Li}(n, \alpha)^{3} \mathrm{H}$ reaction, 12 are detectable in a long background count but do not interfere with analytical measurements.

Quantitative nondestructive measurement of small quantities of hydrogen in materials is important in numerous areas of materials science, such as metallurgy and semi- and superconductor research. Knowledge of the hydrogen concentration in a material has been helpful in interpreting the results of neutron-scattering measurements. ${ }^{13}$ One of the first applications of the cold-neutron PGAA system was to determine hydrogen in several analytical samples of $C_{60}$ fullerene (buckyballs). For example, a 1-g sample, sealed in an aluminum container for the neutron scattering measurements, was found to contain $500 \mu \mathrm{g}$ $\mathrm{H} / \mathrm{g}$, measured to $4 \%$ precision in a 30-min irradiation. In another measurement, hydrogen was sought in a $0.5-\mu \mathrm{m}$ borophosphosilicate glass film deposited on a quarter of a $100-\mathrm{mm}$ silicon wafer; an upper limit of $2 \mu \mathrm{g} / \mathrm{cm}^{2}$ was found.

The quantitative analysis of biological tissue by PGAA is complicated by the scattering of neutrons by hydrogen within the target. The magnitude of this bias depends on the composition and dimensions of the target, and is minimal for spherical targets. ${ }^{14,15}$ Since scattering as well as absorption cross sections for this cold neutron beam are higher by about 
a factor of three than thermal values, this effect is much more important in cold-neutron PGAA. For example, attempts to measure the degree of deuteration of a synthetic C-D-H polymer by cold-neutron PGAA gave results consistent with other methods only if the hydrogen content of the standard was matched to that of the analytical sample.

\section{Conclusions and future plans}

Future enhancements to the counting system will include a Compton suppressor to reduce background (especially for $\mathrm{H}$ ), an automatic sample changer, and a second detector system that will permit $\gamma-\gamma$ coincidence measurements. A new cold source now being designed will increase the neutron fluence rate by a factor of up to five. The difficulties associated with working adjacent to the upper guide - restricted space and Si capture background - may be ameliorated in the future by deflecting the neutron beam away from the guide. Additional improvement in sensitivity may be possible because neutron optics can be used to focus cold neutrons onto a small area. Gains of an order of magnitude in fluence rate may be obtainable with such focusing techniques. ${ }^{16,17}$

We thank W. A. BOWMAN and J. K. LANGLAND for mechanical design and construction, and N. BALSARI, R. L. CAPPELLETTI, J. N. COX, and W. A. KAMTT AKAHARA for supplying analytical samples.

Certain commercial equipment, instruments, or materials are identified in this paper in order to specify the experimental procedures in adequate detail. This identification does not imply recommendation or endorsement by the authors or by the National Institute of Standards and Technology, nor does it imply that the equipment or materials identified are necessarily the best available for the purpose. Contributions of the National Institute of Standards and Technology are not subject to copyright.

References

1. R. ZEISLER, R. M. LINDSTROM, C. A. STONE, M. ROSSBACH, submitted to J. Radioanal. Nucl. Chem., 1991.

2. M. P. FAILEY, D. L. ANDERSON, W. H. ZOLLER, G. E. GORDON, R. M. LINDSTROM, Anal. Chem., 51 (1979) 2209.

3. D. L. ANDERSON, M. P. FAILEY, W. H. ZOLLER, W. B. WALTERS, G. E. GORDON, R. M. LINDSTROM, J. Radioanal. Chem., 63 (1981) 97.

4. R. M. LINDSTROM, R. ZEISLER, M. ROSSBACH, J. Radioanal. Nucl. Chem., 112 (1987) 321.

5. D. L. ANDERSON, W. A. CUNNINGHAM, E. A. MACKEY, Biol. Trace Elem. Res,, 27 (1990) 613.

6. M. E. KITTO, D. L. ANDERSON, in: The Chemistry of Acid Rain (Symp. Ser. 349), R. W. JOHNSON, G. E. GORDON (Eds), Am. Chem. Soc., Washington, D. C., 1987, p. 84.

7. H. J. PRASK, J. M. ROWE, J. J. RUSH, I. G. SCHRÖDER, submitted to J. Res. NIST, 1991.

8. G. P. LAMAZUE, R. G. DOWNING, J. K. LANGLAND, S.-T. HWANG, submitted to J. Radioanal. Nucl. Chem., 1991.

9. J. E. NELSON, Argonne National Laboratory, personal communication, 1989.

10. C. A. STONE, R. ZEISLER, D. H. BLACKBURN, D. A. KAUFFMANN, D. C. CRANMER, in NIST Techn. Note 1285, U.S. Govt. Print. Off., Washington, DC, 1990, p. 116.

11. B. M. RUSTAD, C. J. CHRISTENSEN, B. SKYTTE JENSEN, Nucl. Instrum. Methods, 33 (1965) 155. 
12. M. A. LONE, D. C. SANTRY, W. M. INGLIS, Nucl. Instrum. Methods, 174 (1980) 521.

13. D. A. NEUMANN, J. R. D. COPLEY, R. L. CAPPELLETTI, W. A. KAMITAKAHARA, R. M. LINDSTROM, K. M. CREEGAN, D. M. COX, W. J. ROMANOW, N. COUSTEL, J. P. McCAULEY, Jr., N. C. MALISZEWSKYJ, J. E. FISCHER, A. B. SMITH III, submitted to Phys. Rev. Lett., 1991.

14. J. R. D. COPLEY, C. A. STONE, Nucl. Instrum. Methods, A281 (1989) 593.

15. E, A. MACKEY, G. E. GORDON, R. M. LINDSTROM, D. L. ANDERSON, Anal. Chem., 63 (1991) 288. 16. M. ROSSBACH, O. SCHÄRP, W. KAISER, W. GRAF, A. SCHIRMER, W. FABER, J. DUPPICH, R. ZEISLER, Nucl. Instrum. Methods, B35 (1988) 181.

17. D. F. R. MILDNER, Nucl. Instrum. Methods, A299 (1990) 416. 